\title{
ASSESSMENT OF TWO-WAY R.C SLABS STRENGTHENED USING LOWER CONCRETE LAYER REINFORCED BY FRP BARS
}

\author{
K. M. El-Sayed 1, E. A. El-Kasaby 2, M. A. El-Maasrawy 3 \\ ${ }^{1}$ Associate Prof, Civil Engineering Department, Faculty of Engineering, Benha University, Cairo, Egypt. \\ ${ }^{2}$ Prof, Civil Engineering Department, Faculty of Engineering, Benha University, Cairo, Egypt. \\ ${ }^{3}$ Demonstrators, Civil Engineering Department, Faculty of Engineering, Benha University, Cairo, Egypt.
}

\begin{abstract}
This study presents the efficiency of adding lower concrete layer reinforced by different materials to increase the flexural strength for two-way R.C slabs. Eleven half-scale two-way R.C slab specimens were prepared and tested under four point bending. One of these slabs was unstrengthened and considered as a control specimen. The other specimens were strengthened by using different lower concrete layers reinforced mainly by fiber reinforced polymer (FRP) bars. The parameters of this study included the material type (reinforcement steel, glass fiber and carbon fiber), the thickness of strengthening layer $(30 \& 50 \mathrm{~mm}$ ), spacing between strengthening layer reinforcement bars (100 \& $200 \mathrm{~mm})$, cross sectional area of this reinforcement (A \& 2A) and the type of the strengthening reinforcement (FRP bars \& FRP strips). The experimental results included cracking load, ultimate load, load-deflection relationships, relative ductility, flexural stiffness. The experimental results showed an improvement in the flexural behavior of the strengthened specimens compared to control specimen. The flexural strength of the different strengthened specimens increased by $37 \%$ to $112 \%$ compared to the control specimen.

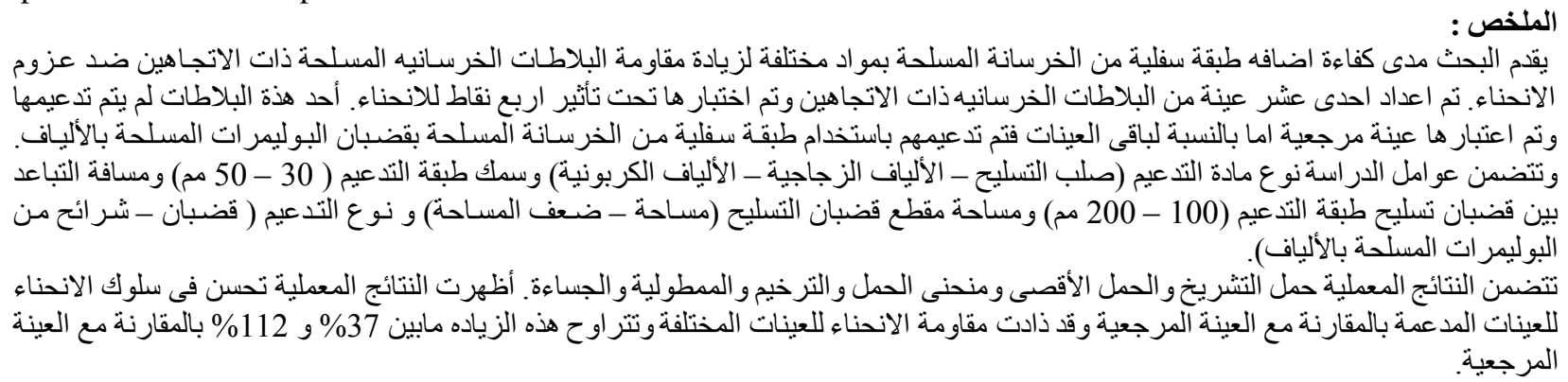

Keywords: Two-way R.C slabs; Flexure Failure; strengthening; tension reinforcement and Fiber Reinforced Polymer.

\section{INTRODUCTION}

Strengthening and repair of reinforced concrete structures is frequently required due to inadequate maintenance, excessive loading, change in use or in code of practice and exposure to adverse environmental condition according to Heiza [1]. Several strengthening techniques have been developed by different traditional techniques including steel plate bonding, external prestressing and reinforced concrete jacting as reported by Fernandes [2], Al-kubaisy and Jumaat, Ezzat and Calixto [3,4,5] . Reinforced concrete solid slabs are used in floors and as decks of bridges. Slabs may span in one direction or in two directions depending on the slab dimensions and the surrounding supporting elements. Different strengthening techniques have been developed so that its serviceability and strength can be restored. Also, the strengthening of the structure should be done taking into consideration the durability aspect. Nowadays, various strengthening techniques are available. However, the selection of the proper technique depends on many factors; such as the deficiency aspect of RC slabs, the cost of the proposed technique, the conditions to which the RC slabs are exposed and the availability of the selected technique due to Heiza [1]. Recently, using FRP materials to strengthen the different $\mathrm{RC}$ elements are gaining popularity due to their superior properties which may exceed the steel. The FRP elements have high strength to weight ratio, ease of application, non-magnetic and non-corrosive. Different FRP systems can be applied to strengthen the RC slabs, these systems include externally bonded FRP strips, near suface mounted

Engineering Research Journal, Vol. 41, No. 1, January 2018, PP: 37-47 
elements and external post tension tendon as reported by Ferrier [6], Foret and Limam [6], Foret [7], Tumalan and Al-Rousan $[9,10]$. This study concerns with evaluation the using of RC lower layer reinforced by FRP bars as a strengthening system for two-way RC slabs.

\section{EXPERIMENAL PROGRAM}

Eleven specimens were cast and tested to investigate strengthening of two-way R.C slabs using lower concrete layer reinforced by FRP bars. The tested specimens in this study were half-scale models of a typical prototype solid slab structure with equal spans of $180 \mathrm{~cm}$ in both directions. All the tested specimens were two-way simply supported slabs.

\subsection{TESTED SPECIMENS}

All the R.C specimens have square shape of $2000 \times 2000 \mathrm{~mm}$ in plan. The thickness of the control specimen and the rest of specimens prior to strengthening is $70 \mathrm{~mm}$. The tested specimens were designed to be simply supported along the four edges using line support on each side. Normal mild steel bars of $8 \mathrm{~mm}$ diameters with $200 \mathrm{~mm}$ spacing in each directions were used as main reinforcement. Full details of the control specimen and the other specimen perior to strengthening, are shown in Fig. 1. The specimens are divided into six groups and reference group, as shown in Table 1.

\subsection{SPECIMENS PREPERATION}

The moulds were prepared and assembled in order to fulfill the required dimensions of the specimens. After the steel reinforcement were installed, concrete mix was placed then the concrete was vibrated mechanically and the concrete surface was finished. After curing period the specimens were left in the lab atmosphere until strengthening date. Ten specimens were strengthened, nine specimens strengthened by FRP element and one specimen by steel bars. Two strengthening techniques were used. For first technique; specimen surface was notched to achieve rough surface using an angle grinder. $10 \mathrm{~mm}$ diameter holes were drilled at the arranged positions of anchors (each $400 \mathrm{~mm}$ in both directions with staggered shape). Anchors were fixed using sikadur $31 \mathrm{CF}$ and the reinforcement bars were installed to the specimen. Surface of specimens was sprinkled by Addibond 65 to improve the bond between original specimen and strengthening layer, then concrete layer was placed and finished. For second technique; Specimen surface removed from any unevenness and Sikadur 330 epoxy resin was applied at the areas where GFRP strips were installed in the two directions by using special roller. Figs. (2, $3 \& 4$ ) illustrate details of strengthening systems.

\subsection{MATERIAL PROPERTIES}

Suitable mix of $305 \mathrm{~kg} / \mathrm{cm}^{2}$ cubic compressive strength after 28 days was used. The constituents of concrete mix and its proportions are presented in Table 2.

CFRP and GFRP bars were locally fabricated using pultrusion process with polyster polymer, then their surfaces were coated by sand layer to improve its bond. The Mechanical properties of FRP bars are given in Table 3. GFRP sheets are, also, locally fabricated. The number of strands in the GFRP strips is the same as in the GFRP bars. The Mechanical properties of GFRP sheets are given in Table 4.

$8 \mathrm{~mm}$ diameter of normal mild steel bars are used to reinforce the tested specimens and, also, were used as reinforcement for strengthening layer for specimen (S3-20-As). 

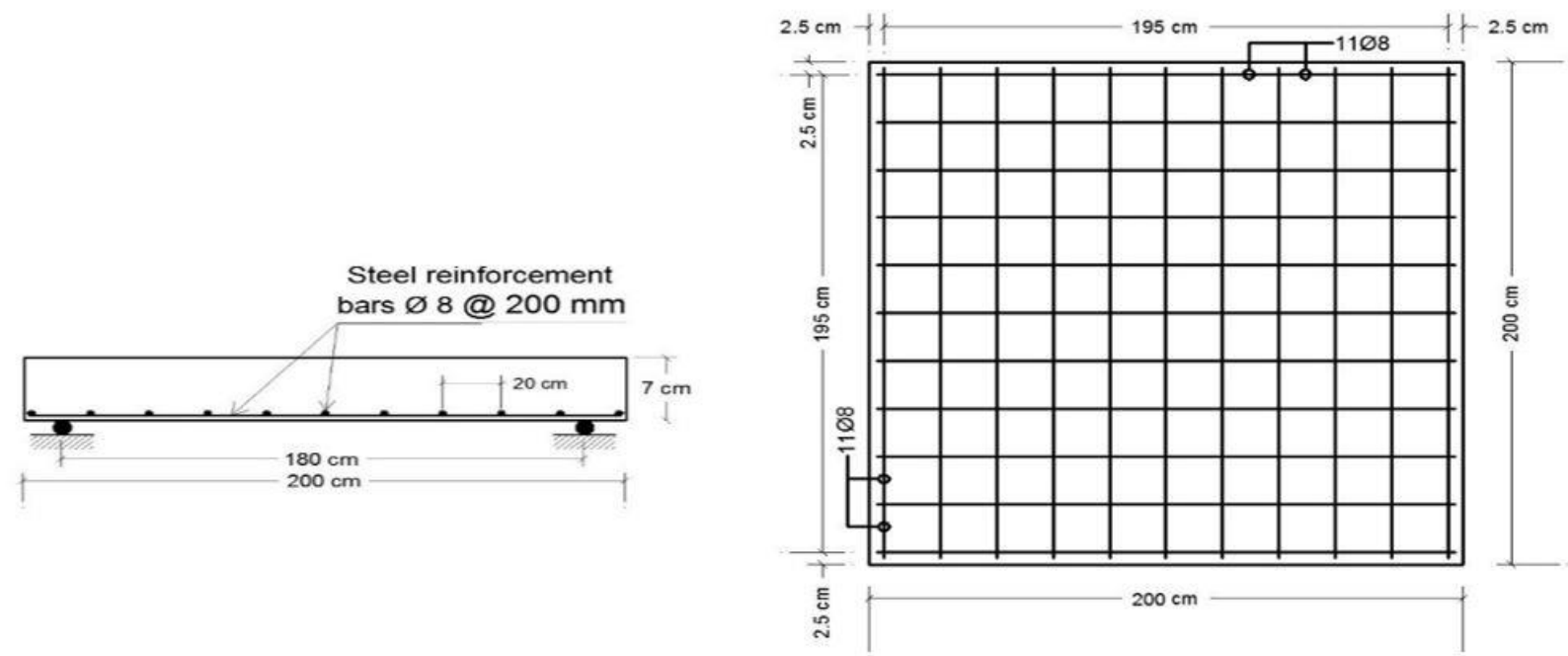

Fig.1: Dimensions and reinforcement details of the control specimen and the other specimens. prior to strengthening

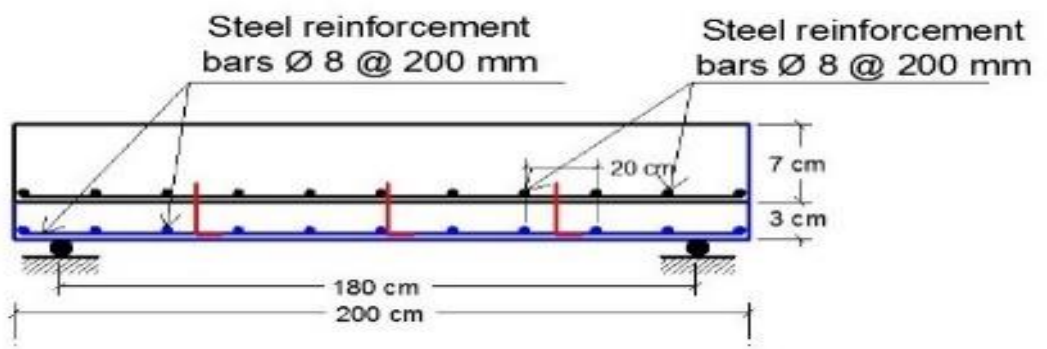

Fig.2: Adding lower concrete layer reinforced by steel reinforcement mesh.

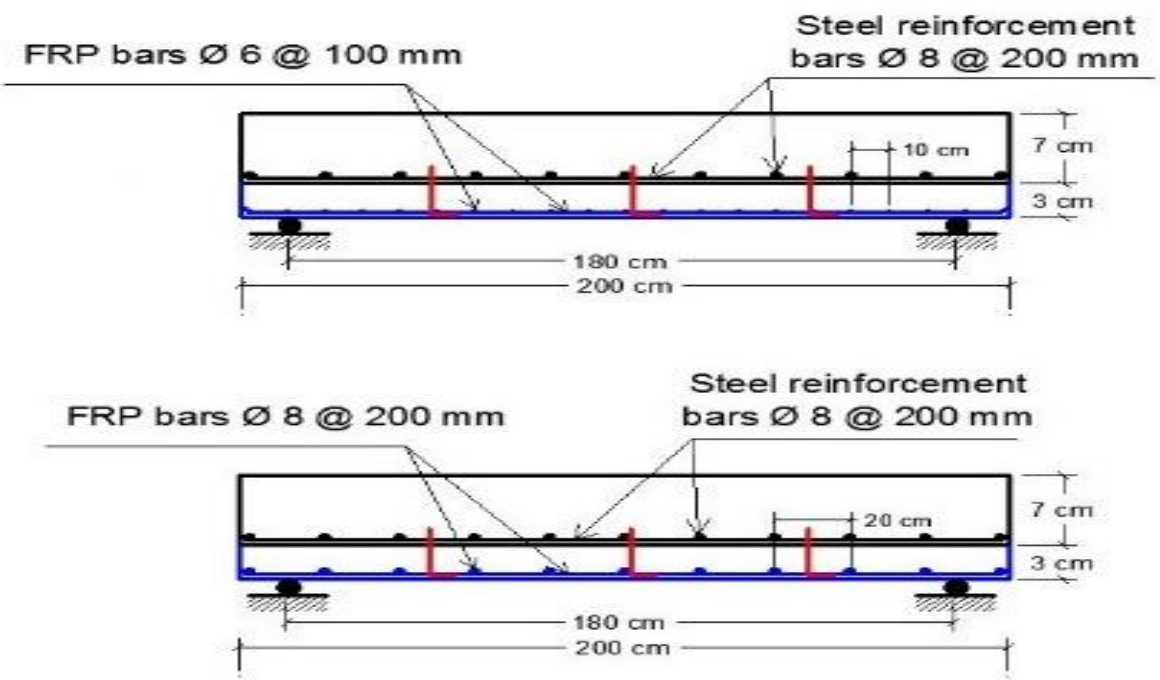

Fig. 3: Adding lower concrete layer reinforced by FRP bars. 


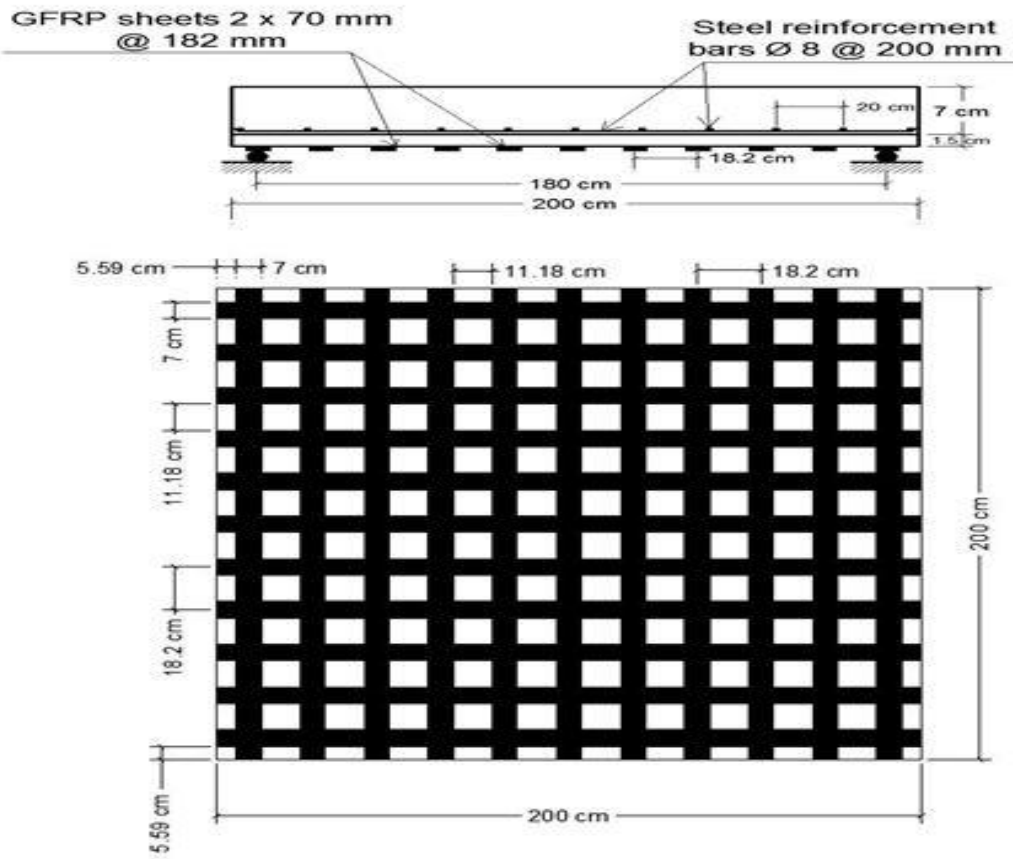

Fig. 4: Adding lower concrete layer reinforced externally by bonded GFRP strips.

Table (1): The experimental test program.

\begin{tabular}{|c|c|c|c|c|c|c|}
\hline \multirow[b]{2}{*}{ Group } & \multirow[b]{2}{*}{ Specimen code } & \multirow[b]{2}{*}{$\begin{array}{l}\text { Specimen } \\
\text { status }\end{array}$} & \multicolumn{4}{|c|}{ Strengthening layer } \\
\hline & & & Reinforcement & $\begin{array}{c}\text { Layer } \\
\text { thickness } \\
(\mathrm{mm})\end{array}$ & $\begin{array}{c}\text { Bars/sheet } \\
\text { spacing } \\
(\mathrm{mm})\end{array}$ & $\begin{array}{c}* * \text { Area of } \\
\text { reinforcement } \\
\text { bars/sheets } \\
\left(\mathrm{mm}^{2}\right)\end{array}$ \\
\hline Reference & $\mathrm{C}$ & control & --- & --- & --- & --- \\
\hline $\begin{array}{l}\text { First } \\
\text { group }\end{array}$ & S-3-20-As & \multirow{10}{*}{ 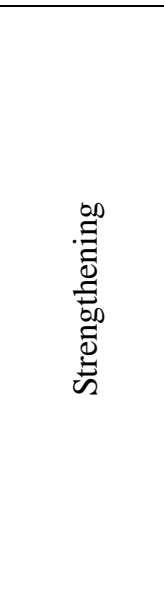 } & Steel bars & 30 & 200 & 50.3 \\
\hline \multirow{2}{*}{$\begin{array}{c}\text { Second } \\
\text { group }\end{array}$} & $\mathrm{C}-3-10-\mathrm{Ac} / 2$ & & \multirow{2}{*}{ CFRP bars } & \multirow{2}{*}{30} & 100 & 28.3 \\
\hline & C-3-20-Ac & & & & 200 & 50.3 \\
\hline \multirow{2}{*}{$\begin{array}{l}\text { Third } \\
\text { group }\end{array}$} & G-3-10-Ag/2 & & \multirow{2}{*}{ GFRP bars } & \multirow{2}{*}{30} & 100 & 28.3 \\
\hline & G-3-20-Ag & & & & 200 & 50.3 \\
\hline \multirow{2}{*}{$\begin{array}{l}\text { Fourth } \\
\text { group }\end{array}$} & G-5-10-Ag/2 & & \multirow{2}{*}{ GFRP bars } & \multirow{2}{*}{50} & 100 & 28.3 \\
\hline & G-5-20-Ag & & & & 200 & 50.3 \\
\hline \multirow{2}{*}{$\begin{array}{l}\text { Fifth } \\
\text { group }\end{array}$} & G-3-10-Ag & & \multirow{2}{*}{ GFRP bars } & 30 & 100 & 50.3 \\
\hline & G-5-10-Ag & & & 50 & 100 & 50.3 \\
\hline $\begin{array}{l}\text { Sixth } \\
\text { group }\end{array}$ & GS-1.5-20-Ag & & GFRP sheets* & 15 & 200 & 70.0 \\
\hline
\end{tabular}

* Externally bonded

** The area of steel or FRP cross-sectional 
Table (2): The constituents of concrete mix

\begin{tabular}{|c|c|c|c|}
\hline $\begin{array}{c}\text { Cement } \\
\left(\mathrm{Kg} / \mathrm{m}^{3}\right)\end{array}$ & $\begin{array}{c}\text { Crushed } \\
\text { dolomite } \\
\left(\mathrm{Kg} / \mathrm{m}^{3}\right)\end{array}$ & $\begin{array}{c}\text { Sand } \\
\left(\mathrm{Kg} / \mathrm{m}^{3}\right)\end{array}$ & $\begin{array}{c}\text { Water } \\
\left(\mathrm{Liter} / \mathrm{m}^{3}\right)\end{array}$ \\
\hline 350 & 1260 & 630 & 175 \\
\hline
\end{tabular}

Table (3): Dimensional and mechanical properties of FRP bars

\begin{tabular}{|c|c|c|c|c|}
\hline Property & \multicolumn{2}{|c|}{ GFRP bars } & \multicolumn{2}{|c|}{ CFRP bars } \\
\hline $\begin{array}{c}\text { Diameter of } \\
\text { bars }\end{array}$ & $8 \mathrm{~mm}$ & $6 \mathrm{~mm}$ & $8 \mathrm{~mm}$ & $6 \mathrm{~mm}$ \\
\hline Area of bars & $\begin{array}{c}50 \\
\mathrm{~mm}^{2}\end{array}$ & $\begin{array}{l}28.3 \\
\mathrm{~mm}^{2}\end{array}$ & $\begin{array}{c}50 \\
\mathrm{~mm}^{2}\end{array}$ & $\begin{array}{l}28.3 \\
\mathrm{~mm}^{2}\end{array}$ \\
\hline Area of fibers & $\begin{array}{l}14.55 \\
\mathrm{~mm}^{2}\end{array}$ & $\begin{array}{l}7.75 \\
\mathrm{~mm}^{2}\end{array}$ & $\begin{array}{l}12.8 \\
\mathrm{~mm}^{2}\end{array}$ & $\begin{array}{c}6.4 \\
\mathrm{~mm}^{2}\end{array}$ \\
\hline $\begin{array}{c}\text { Fiber ratio by } \\
\text { area }\end{array}$ & $30 \%$ & $28 \%$ & $26 \%$ & $23 \%$ \\
\hline $\begin{array}{c}\text { Tensile strength } \\
\text { of fibers }\end{array}$ & \multicolumn{2}{|c|}{$13700 \mathrm{~kg} / \mathrm{cm}^{2}$} & \multicolumn{2}{|c|}{$14000 \mathrm{~kg} / \mathrm{cm}^{2}$} \\
\hline $\begin{array}{l}\text { Modulas of } \\
\text { elasticity of } \\
\text { fibers }\end{array}$ & \multicolumn{2}{|c|}{$900000 \mathrm{~kg} / \mathrm{cm}^{2}$} & \multicolumn{2}{|c|}{$2100000 \mathrm{~kg} / \mathrm{cm}^{2}$} \\
\hline Strain at failure & \multicolumn{2}{|c|}{$15000 \times 10-6$} & \multicolumn{2}{|c|}{$6600 \times 10-6$} \\
\hline
\end{tabular}

Table (4): Dimensional and mechanical properties of FRP sheets

\begin{tabular}{|c|c|}
\hline Property & GFRP \\
\hline $\begin{array}{c}\text { Fabric design } \\
\text { thickness }\end{array}$ & $1 \mathrm{~mm}$ \\
\hline Fabric width & $7 \mathrm{~cm}$ \\
\hline Tensile strength & $22500 \mathrm{~kg} / \mathrm{cm}^{2}$ \\
\hline Modulus of elasticity & $760000 \mathrm{~kg} / \mathrm{cm}^{2}$ \\
\hline Strain at failure & $2.80 \%$ \\
\hline
\end{tabular}

\subsection{TEST SETUP AND TESTING PROCEDURE}

The loading system consisted of rigid system of reaction frame, 100 ton capacity, and hydraulic jack, 100 ton capacity, connected to electrical pump. The specimens were tested under vertical concentrated load which is distributed to four equal points concentrated loads acting on the slab upper surface by means of rigid steel frame, as shown in Fig. 5. The specimens were simply supported on line supports at the four sides over a clear span of $1800 \mathrm{~mm}$. Vertical deflection, first cracking load and ultimate failure load, were recorded. Five linear variable differential transducers (LVDTs) mounted at the bottom soffit of the specimen for measuring deflections at bottom face (tension side), as shown in Fig. 6. Cracks propagation were monitored after each load increment up to failure.

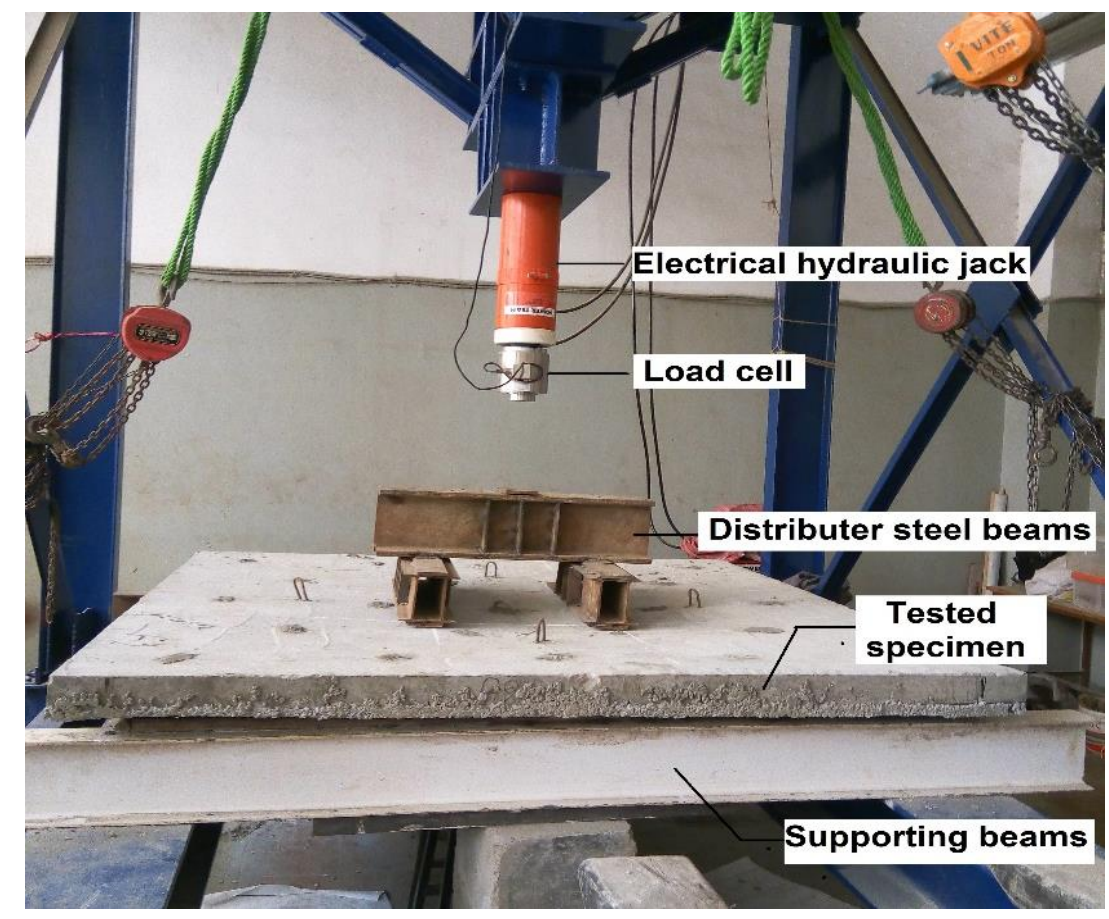

Fig.5: The test set-up. 


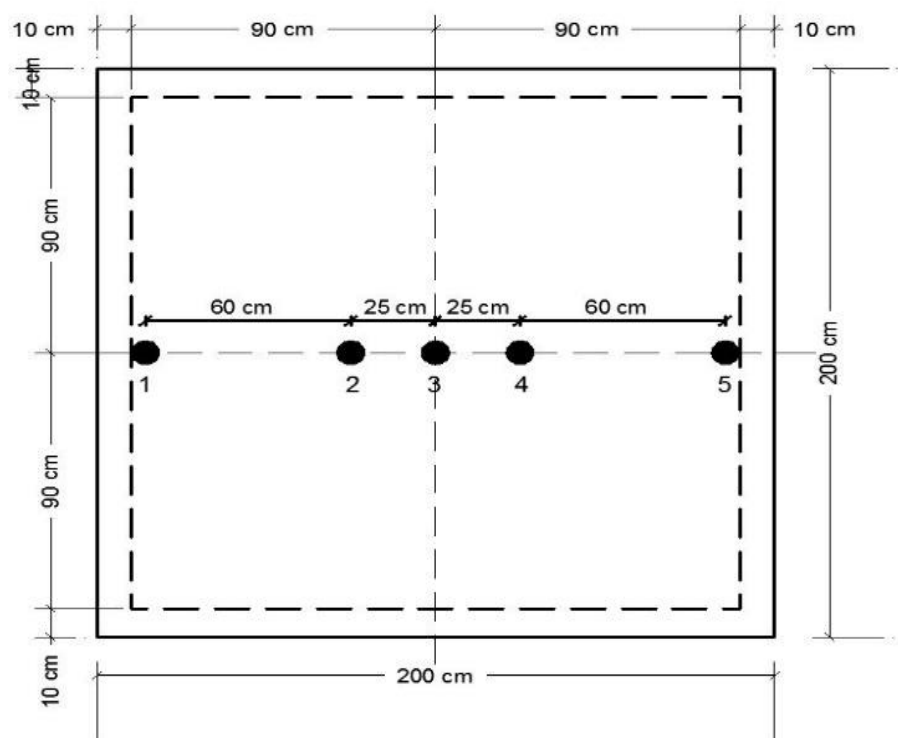

Fig.6: LVDT locations (bottom side).

\section{EXPERIMENTAL RESULTS AND} DISCUSSION

For the all tested specimens, the relationship between the central deflection at mid-point (point 3) and the applied load was plotted and the crack propagation was monitored with load increasing till failure, Also, the cracking load and ultimate load were recorded. Comparisons between the results of different specimens were carried out to reveal the effect of the parameters considered in this study.

\subsection{LOAD DEFLECTION RELATIONSHIP}

All the strengthening systems used in this study led to a significant increase in the strength and the rigidity of the strengthened specimens in comparison with the control specimen. At the same loading level, lower deflection values were recorded for strengthened specimens, either with steel reinforcement, GFRP or CFRP bars, in comparison with the control specimen, as shown in Figs. (7 to 16).

\subsubsection{EFFECT OF STRENGTHENING LAYER THICKNESS}

The used layers thickness are 30 \& $50 \mathrm{~mm}$, respectively. The effect of this parameter could be observed by studying the behavior of specimens G-3$10-\mathrm{Ag} / 2$ \& G-5-10-Ag/2, specimens G-3-20-Ag \& G-5$20-\mathrm{Ag}$ and specimens G-3-10-Ag \& G-5-10-Ag, as shown in Figs. (7, $8 \&$ \&). As expected, adding the strengthening layer led to improve the flexural behavior. The ultimate load was higher than that of control specimen by $76 \%$ and $112 \%$ for strengthening layer with thickness $30 \mathrm{~mm}$ and $50 \mathrm{~mm}$, respectively. Also, the deflection was reduced by $83.8 \%$ and $97.5 \%$, respectively at ultimate recorded load of control specimen.

\subsubsection{EFFECT OF STRENGTHENING MATERIAL TYPE}

The effect of this parameter could be observed by studying the behavior of specimens S-3-20-As, C-3-20Ac \& G-3-20-Ag, as shown in Fig. 10, which correspond to three types of strengthening materials: steel reinforcement bars, CFRP bars, and GFRP bars.

All the materials used in strengthening led to improve the flexural behavior, where the ultimate load was increased and the deflection at the same loading values was decreased. CFPR bars were the best material, the ultimate load was increasded by $68 \%$. However, GFRP bars and steel bars have close ultimate load of $137 \%$ and $138 \%$, respectively of the corresponding control specimen value. the deflections at ultimate load of control specimen was reduced by $80.6 \%, 75.3 \%$ and $92 \%$ for specimens strengthened by CFRP, GFRP and steel bars, respectively.

\subsubsection{EFFECT OF SPACING BETWEEN REINFORCEMENT BARS}

The effect of this parameter could be observed by studying the behavior of three specimen groups (G-310-Ag/2 \& G-3-20-Ag, G-5-10-Ag/2 \& G-5-20-Ag and C-3-10-Ac/2 \& C-3-20-Ac), as shown in Figs. (11, 12 $\&$ 13). The used spacings are $100 \& 200 \mathrm{~mm}$, respectively.

Reducing the spacing between bars with keeping the same cross-sectional area led to increase the ultimate load by 53\%, 69\% and $95 \%$ for the three studied 
groups, respectively compared to that recorded for the control specimen.

The effect of this parameter was more pronounced for CFRP, not only on the ultimate load but also on the deflection reduction, which decreased at maximum recorded load of control specimen by $93.1 \%$ when the spacing was reduced from $200 \mathrm{~mm}$ to $100 \mathrm{~mm}$.

\subsubsection{EFFECT OF X-SECTIONAL AREA OF REINFORCEMENT BARS}

The effect of this parameter could be observed by studying the behavior of specimens G-3-10-Ag/2 \& G3-10-Ag and specimens G-5-10-Ag/2 \& G-5-10-Ag, as shown in Figs. (14 \& 15). For the used areas A \& $2 \mathrm{~A}$ $\mathrm{mm}$, respectively.

As expected, doubling the $\mathrm{x}$-sectional area of bars led to increase the ultimate load by $76 \%$ and $112 \%$ for specimens strengthening by adding $\mathrm{RC}$ layer reinforced by GFRP bars with thickness $30 \mathrm{~mm}$ and $50 \mathrm{~mm}$, respectively, also, the deflection at maximum recorded load of control specimen was reduced by $83.8 \%$ and $97.5 \%$, respectively in compared with control specimen.

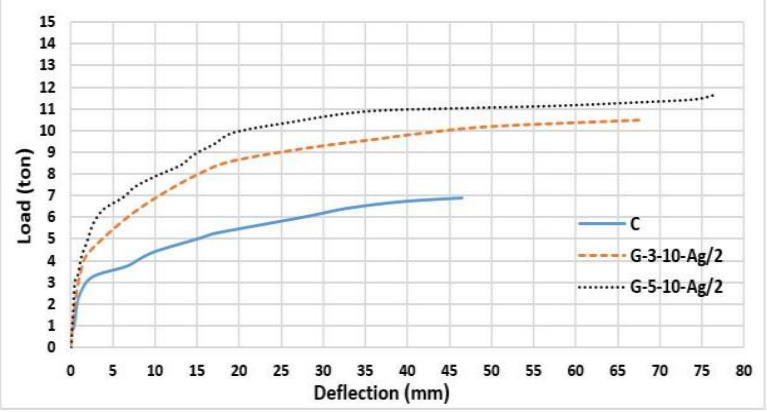

Fig.7: Comparison between Load-Central deflection relationships of the specimens (G-3-10-Ag/2), (G-5-10-Ag/2), and (C).

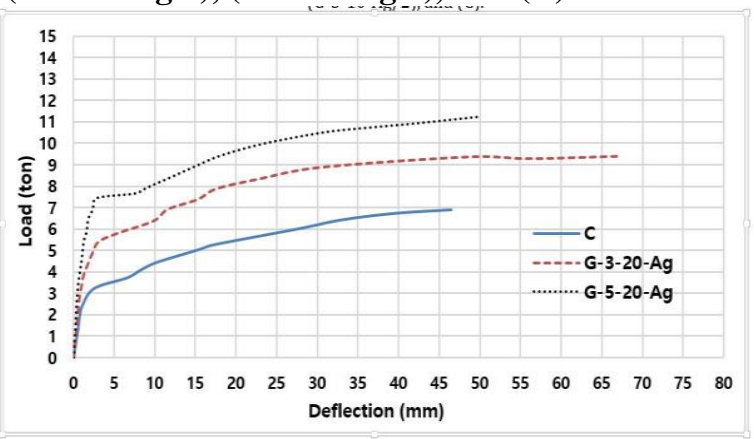

Fig.8: Comparison between Load-Central deflection relationships of the specimens (G-3-20-Ag), (G-5-20-Ag), and (C).

\subsubsection{EFFECT OF STRENGTHENING METHOD}

The effect of this parameter could be observed by studying the behavior of specimens (G-3-20-Ag \& GS1.5-20-Ag), as shown in Fig. 16, which correspond to two types of strengthening methods. The first type was adding $30 \mathrm{~mm}$ lower concrete layer reinforced by GFRP bars mesh, and the second was adding $15 \mathrm{~mm}$ lower concrete layer reinforced by externally bonded GFRP sheets.

The two strengthening techniques led to increase the ultimate load by $53 \%$ and $71 \%$ for the first and second technique, respectively compared to the control specimen, also, the deflection at maximum recorded load of control specimen was reduced by $75.3 \%$ and $5.9 \%$, respectively in compared with control specimen.

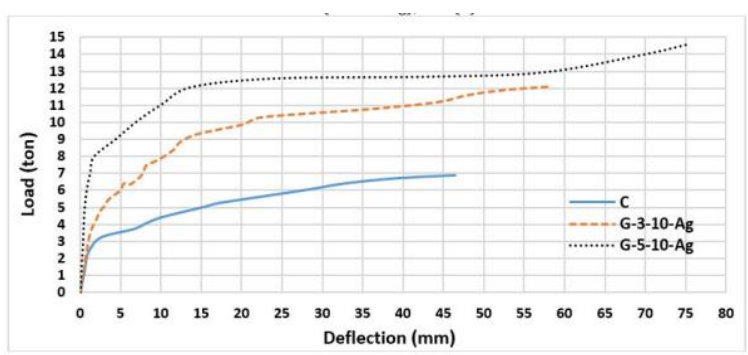

Fig.9: Comparison between Load-Central deflection relationships of the specimens (G-3-10-Ag), (G-5-10-Ag), and (C).

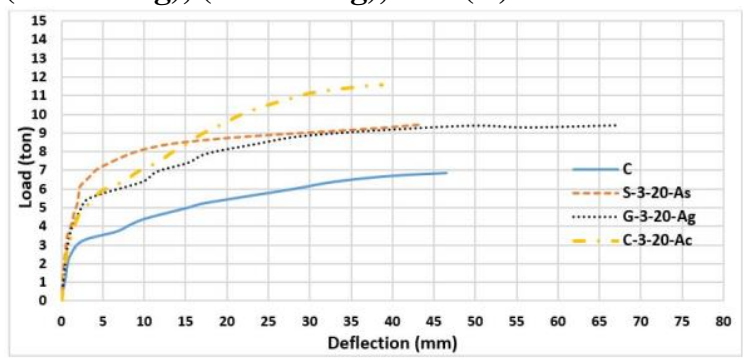

Fig.10: Comparison between Load-Central deflection relationships of the specimens (S-3-20-As), (G-3-20-Ag), (C-3-20-Ac), and (C). 


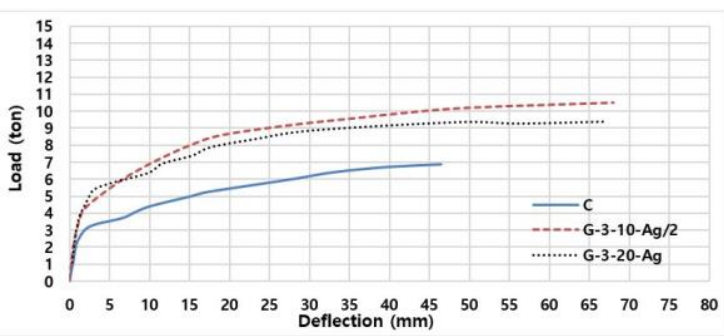

Fig.11: Comparison between Load-Central deflection relationships of the specimens (G-3-10-Ag/2), (G-3-20-Ag), and (C).

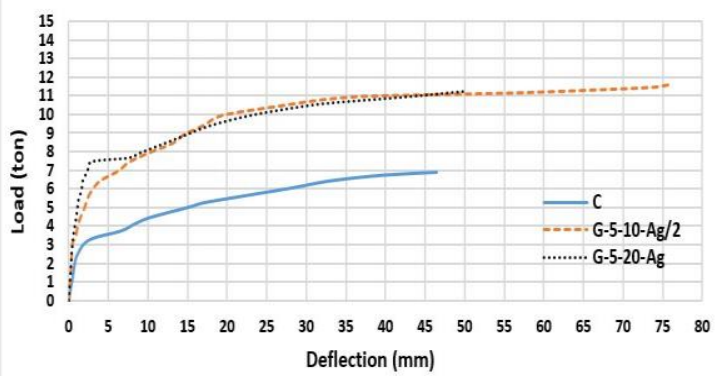

Fig.12: Comparison between Load-Central deflection relationships of the specimens (G-5-10-Ag/2), (G-5-20-Ag), and (C).

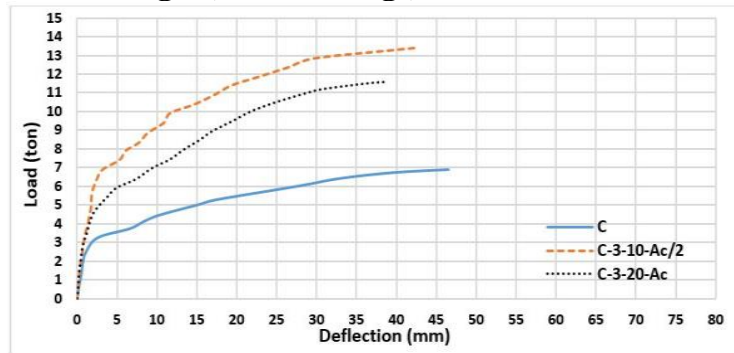

Fig.13: Comparison between Load-Central deflection relationships of the specimens $(\mathrm{C}-3-10-$ $\mathrm{Ac} / 2),(\mathrm{C}-3-20-\mathrm{Ac})$, and (C).

\subsection{CRACKING AND ULTIMATE LOAD}

Table. 5 presents the deflection and load values at first cracking and at failure, and also the ductility and the stiffness indices, for all the tested specimens. The specimen (G-5-10-Ag), had the highest ultimate load, higher than that of control specimen by $112 \%$. This was expected because the former specimen has the more effective strengthening system with a lower concrete layer of $50 \mathrm{~mm}$ thickness (the biggest thickness) reinforced by GFRP bars of double cross sectional area.

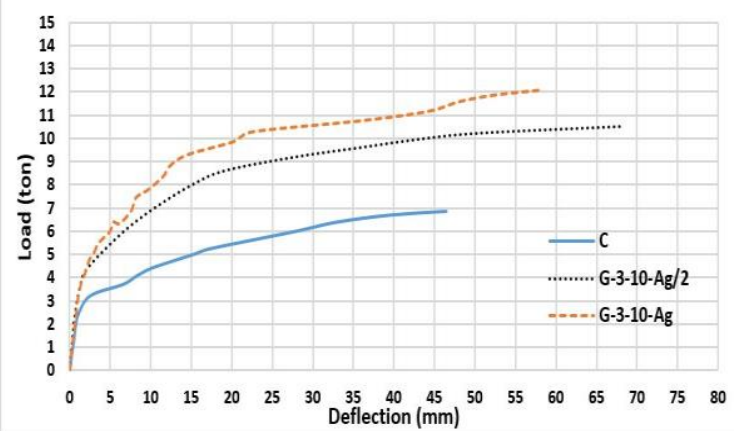

Fig.14: Comparison between Load-Central deflection relationships of the specimens (G-3-10-Ag/2), (G-3-10-Ag), and (C).

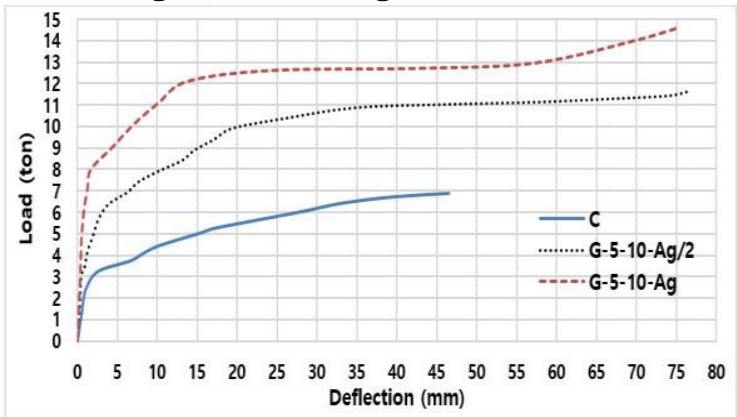

Fig.15: Comparison between Load-Central deflection relationships of the specimens (G-5-10$\mathrm{Ag} / 2),(\mathrm{G}-5-10-\mathrm{Ag})$, and (C).

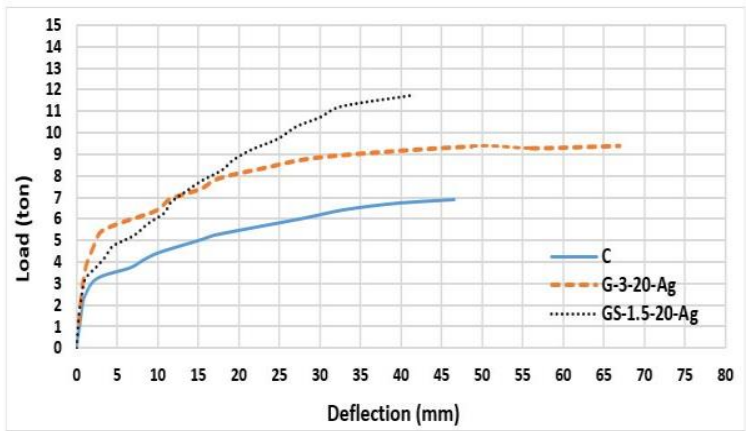

Fig.16: Comparison between Load-Central deflection relationships of the specimens (G3-20-Ag), (GS-1.5-20-Ag), and (C).

The specimen (C-3-10-Ac/2) had the highest ultimate load value, compared to all the specimens of lower layer of $30 \mathrm{~mm}$ thickness, the ultimate load of this specimen was higher than that of control specimen by $95 \%$. The high tensile strength of carbon fiber and the small spacing between the CFRP bars (high surface area) may explain the efficient strengthening system of specimen (C-3-10-Ac/2). Fig. 17 shows cracking load and ultimate load values for all specimens. 
Table (5): Main results of the tested specimens

\begin{tabular}{|c|c|c|c|c|c|c|c|c|c|}
\hline \multirow{2}{*}{ Specimen code } & \multicolumn{2}{|c|}{$1^{\text {st }}$ cracking } & \multicolumn{2}{|c|}{ Ultimate } & \multirow{2}{*}{$\frac{\begin{array}{c}\mathrm{P}_{\text {ult }} \\
\text { (specimen) }\end{array}}{\begin{array}{c}\mathrm{P}_{\text {ult }} \\
\text { (control) }\end{array}}$} & \multirow{2}{*}{$\begin{array}{l}\text { Ductility } \\
\Delta_{\mathrm{ul}} / \Delta_{\mathrm{cr}}\end{array}$} & \multirow{2}{*}{$\begin{array}{c}\mathrm{K}_{\mathrm{i}}= \\
\mathrm{P}_{\mathrm{cr}} / \Delta_{\mathrm{cr}} \\
(\mathrm{t} / \mathrm{mm})\end{array}$} & \multirow{2}{*}{$\begin{array}{c}\mathrm{P}_{\mathrm{ul}}-\mathrm{P}_{\mathrm{cr}} \\
\mathrm{K}_{\mathrm{u}}= \\
\Delta_{\mathrm{ul}}-\Delta_{\mathrm{cr}} \\
\\
(\mathrm{t} / \mathrm{mm})\end{array}$} & \multirow{2}{*}{$\begin{array}{c}\begin{array}{c}\text { Stiffness } \\
\text { Degradation }\end{array} \\
\frac{\left(\mathrm{K}_{\mathrm{i}}-\mathrm{K}_{\mathrm{u}}\right) \times 100}{\mathrm{~K}_{\mathrm{i}}}\end{array}$} \\
\hline & $\begin{array}{l}\text { Load } \\
\text { (ton) }\end{array}$ & $\begin{array}{c}\Delta_{\mathrm{cr}} \\
\text { def. } \\
(\mathrm{mm})\end{array}$ & $\begin{array}{l}\text { Load } \\
\text { (ton) }\end{array}$ & $\begin{array}{c}\Delta_{\mathrm{ul}} \\
\text { ult. } \\
(\mathrm{mm})\end{array}$ & & & & & \\
\hline $\mathrm{C}$ & 2.00 & 0.79 & 6.88 & 46.50 & 1.00 & 58.86 & 2.53 & 0.11 & 95.79 \\
\hline S-3-20-As & 4.00 & 1.23 & 9.46 & 43.10 & 1.38 & 34.92 & 3.24 & 0.13 & 95.98 \\
\hline $\mathrm{C}-3-10-\mathrm{Ac} / 2$ & 5.00 & 1.75 & 13.40 & 42.17 & 1.95 & 24.06 & 2.85 & 0.21 & 92.71 \\
\hline $\mathrm{C}-3-20-\mathrm{Ac}$ & 4.00 & 1.50 & 11.58 & 38.78 & 1.68 & 25.85 & 2.67 & 0.20 & 92.38 \\
\hline G-3-10-Ag/2 & 4.50 & 2.50 & 10.50 & 68.00 & 1.53 & 27.20 & 1.80 & 0.09 & 94.91 \\
\hline G-3-20-Ag & 4.00 & 1.18 & 9.40 & 66.90 & 1.37 & 56.79 & 3.40 & 0.08 & 97.58 \\
\hline G-5-10-Ag/2 & 5.10 & 2.00 & 11.64 & 76.35 & 1.69 & 38.17 & 2.55 & 0.09 & 96.55 \\
\hline G-5-20-Ag & 4.00 & 0.74 & 11.23 & 50.00 & 1.63 & 67.27 & 5.38 & 0.15 & 97.27 \\
\hline G-3-10-Ag & 3.00 & 0.98 & 12.10 & 58.46 & 1.76 & 59.55 & 3.06 & 0.16 & 94.82 \\
\hline G-5-10-Ag & 8.00 & 1.67 & 14.59 & 75.25 & 2.12 & 45.09 & 4.79 & 0.09 & 98.13 \\
\hline GS-1.5-20-Ag & 5.50 & 7.10 & 11.74 & 41.16 & 1.71 & 5.14 & 0.69 & 0.19 & 72.62 \\
\hline
\end{tabular}

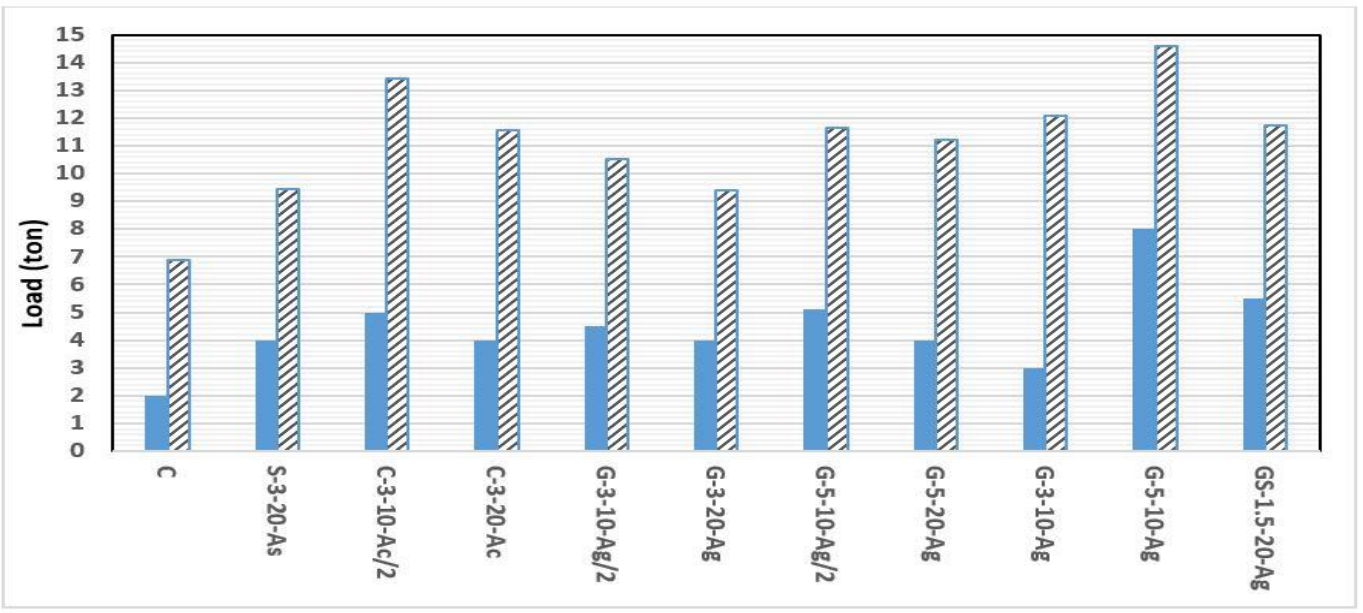

Fig.17: Cracking and ultimate load for all test specimens

\subsection{DUCTILITY}

Ductility means the ability of a member to undergo inelastic deformations beyond the yield deformation without any considerable loss of load bearing capacity. The ductility of the specimens was considered as the ratio of the deflection at ultimate load to the deflection at first crack load as shown in Table. 5. Generally, specimens strengthened by adding lower concrete layer reinforced by GFRP bars are better than specimens strengthened by adding lower concrete layer reinforced by CFRP bars due to lower modulas of elasticity for GFRP than CFRP, but specimen strengthened by externally bonded GFRP sheets had the less ductility at all due to the high ability of sheets to debond.

\subsection{STIFFNESS}

The un-cracked stiffness $\mathrm{Ki}$ and the ultimate stiffness $\mathrm{Ku}$ were obtained from the load-deflection values of the tested specimens, as presented in Table. 5. It shows that the un-cracked stiffness (Ki) is almost, increased for the majority of the tested specimens. Adding lower concrete layer reinforced by reinforcement steel, CFRP\& GFRP bars mesh led to increase $\mathrm{Ki}$ while adding lower concrete layer reinforced by externally bonded GFRP sheets led to decrease Ki. 


\subsection{THE FAILURE MODE}

All the tested specimens were loaded until failed due to flexure. For all specimens, the first crack was recorded, cracks propagation were monitored, and the plane of failure was observed to investigate the cracking and failure behavior. Two modes of failure are expected, the first was flexure failure of the strengthening slab as a one units, while the second type is the debonding between the strengthening layer and the original slab. All specimens were failed by flexure failure with partial debonding between the strengthening layer and the original slab. Table. 5. shows the load value corresponding to cracking initiation (Pcr). Cracks began firstly at the slab tension side under the four point load forming square lines. As the applied loads increase the number and width of the cracks increase then new cracks develop and begin to propagate towards the slab edges in diagonal directions towards the slab corners. The failure surface of the tested specimens was carefully recorded. Strengthening systems led to an increase of the first crack load and, also, its rates to the ultimate load of the tested specimens. A typical crack pattern is shown in Fig. 18 \& 19 for control specimen and specimen G-3-10-Ag/2, respectively. For specimen GS-1.5-20-Ag, where GFRP strips were externally bonded, it was failed due to debonding of the strengthening strips, as shown in Fig. 20.

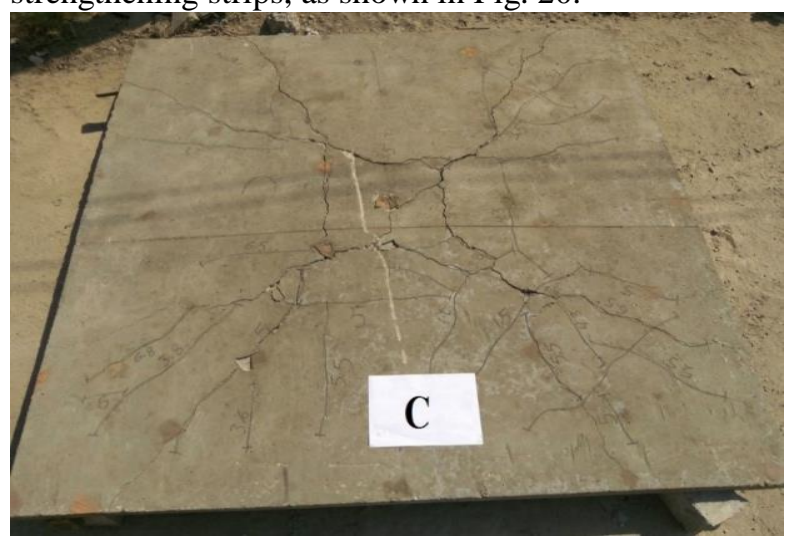

Fig.18: Cracking pattern of $\operatorname{specimen}(C)$.

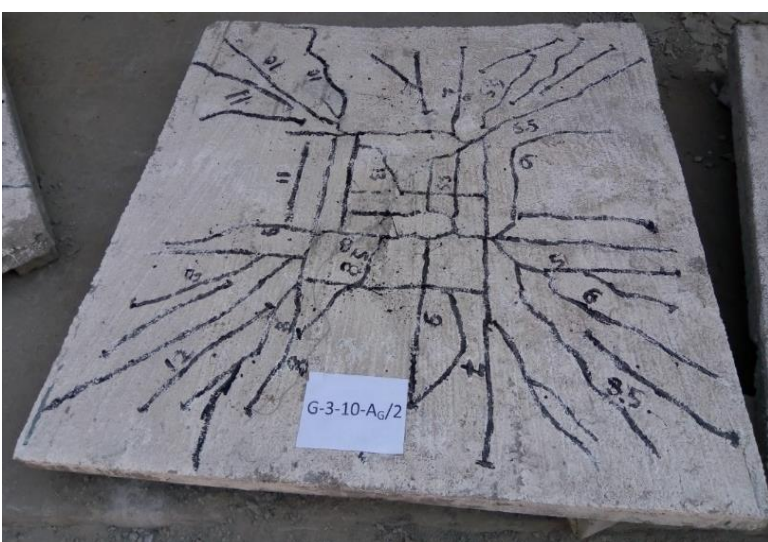

Fig.19: Cracking pattern of specimen (G-3-10$\mathrm{Ag} / 2$ ).

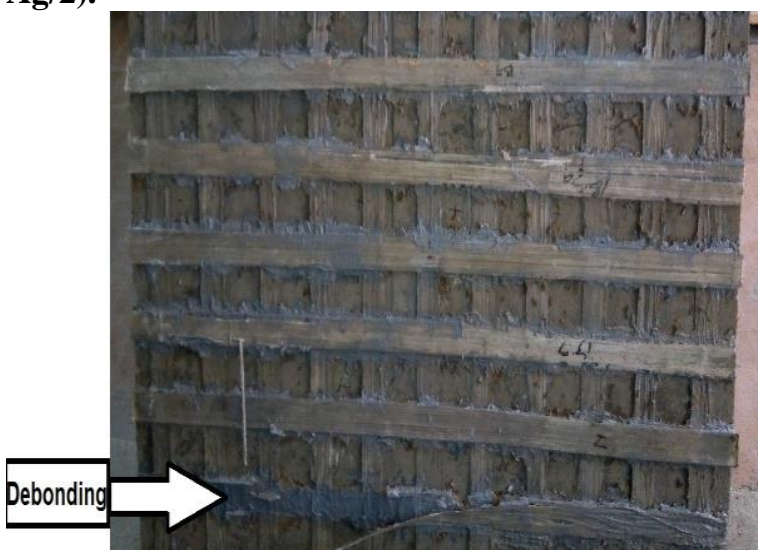

Fig.20: Deponding shape for specimen (GS-1.5-20Ag).

\section{CONCLUSIONS}

The main goal of the current research is examining the effect of adding R.C layer reinforced by FRP elements on the structural behavior of two-way R.C slabs in terms of strength and flexure. From the experimental and numerical results, the following conclusions could be drawn as below:-

1. Strengthening systems were effective in improving the flexural strength of the tested specimens by a range from $37 \%$ to $112 \%$, also, the deflections were reduced significally by a range from $75.3 \%$ to $97.5 \%$ compared to the control specimen at its ultimate load.

2. All methods used for strengthening of slabs in this research were effective to restore and improve the structural performance in terms of flexural rigidity, ultimate stiffness $(\mathrm{Ku})$, initial cracking load and the ultimate carrying capacity.

3. All the used materials in this research led to increase the initial cracking load by $50 \%$ to $300 \%$ and the ultimate load capacity also increased by $37 \%$ to $112 \%$. 
4. For the three types of strengthening material (reinforcement steel, carbon fiber and glass fiber); the specimens (S-3-20-As, C-3-20-Ac \& G-3-20$\mathrm{Ag}$ ) achieved an increase in the initial cracking load by $100 \%$, for the three specimens, and the ultimate capacity by $38 \%, 68 \%$ and $37 \%$, respectively.

5. For the strengthening layer thickness (30 \& $50 \mathrm{~mm})$; the specimens (G-3-10-Ag/2 \& G-5-10-Ag/2) achieved an increase in the initial cracking load by $125 \%$ and $155 \%$, respectively, and the ultimate capacity by $53 \%$ and $69 \%$, respectively, also, the specimens (G-3-20-Ag \& G-5-20-Ag) achieved an increase in the initial cracking load by $100 \%$ and $100 \%$, respectively, and the ultimate capacity by $37 \%$ and $63 \%$, respectively, also, the specimens (G3-10-Ag \& G-5-10-Ag) achieved an increase in the initial cracking load by $50 \%$ and $300 \%$, respectively, and the ultimate capacity by $76 \%$ and $112 \%$, respectively.

6. For the spacing between reinforcement bars $(100 \&$ $200 \mathrm{~mm}$ ); the specimens (G-3-10-Ag/2 \& G-3-20$\mathrm{Ag}$ ) achieved an increase in the initial cracking load by $125 \%$ and $100 \%$, respectively, and the ultimate capacity by $53 \%$ and $37 \%$, respectively, also, the specimens (G-5-10-Ag/2 \& G-5-20-Ag) achieved an increase in the initial cracking load by $155 \%$ and $100 \%$, respectively, and the ultimate capacity by $69 \%$ and $63 \%$, respectively, also, the specimens (C3-10-Ac/2 \& C-3-20-Ac) achieved an increase in the initial cracking load by $150 \%$ and $100 \%$, respectively, and the ultimate capacity by $95 \%$ and $68 \%$, respectively.

7. For the reinforcement bars area (A \& 2A); the specimens (G-3-10-Ag/2 \& G-3-10-Ag) achieved an increase in the initial cracking load by $125 \%$ and $50 \%$, respectively, and the ultimate capacity by $53 \%$ and $76 \%$, respectively, also, the specimens (G-5-10$\mathrm{Ag} / 2$ \& G-5-10-Ag) achieved an increase in the initial cracking load by $155 \%$ and $300 \%$, respectively, and the ultimate capacity by $69 \%$ and $112 \%$, respectively.

8. For the strengthening method (FRP bars \& FRP strips); the specimens (G-3-20-Ag \& GS-1.5-20-Ag) achieved an increase in the initial cracking load by $100 \%$ and $175 \%$, respectively, and the ultimate capacity by $37 \%$ and $71 \%$, respectively.

9. For all the tested specimens, it was observed that the failure was flexural failure due to partial debonding between the strengthening layer and the original slab also, it was observed that the cracks began firstly at the slab tension side under four point load forming square line and with increasing the load, number and width of the cracks increase and begin to propagate in diagonal direction towards the slab edge.
10. In general, the specimen (G-5-10-Ag) was the best one, which led to the highest ultimate capacity between the tested specimens. However the CFRP bars was the best material, which led to the highest improvement in the rigidity and ultimate capacity of the tested specimens.

\section{REFERENCES}

1. Heiza K, Nabil A, Maleka N, Tayel M. (2014). State of the art review: Strengthening of reinforced concrete structures different strengthening techniques 16th international conference on nano technology in construction, Cairo, Egypt, March.

2. Fernandes H, Lucio V, Ramos A (2017). Strengthening of RC slabs with reinforced concrete overlay on tensile face. Engineering structure, 137, $540-550$.

3. Al-kubaisy, MA, Jumaat MZ (2000). Flexural behavior of reinforced concrete slabs with ferrocement tensions cover. J.Constr.Build. Mater, 14, 245-252.

4. Ezzat, H F, Yousry BI, Yasser SK (1996). Repairing reinforced concrete slabs using ferrocement laminates. 7th international colloquium on structural and geotechnical engineering, Cairo, Egypt, December.

5. Calixto JM, Pires E F, Lima SA, Piancastelli EM (2003). Behavior of reinforced concrete slabs strengthened in flexure by concrete overlays. ACI Structural Journal 229, 389-406.

6. Michel L, Ferrier E, Agbossou A, Hamelin P (2009). Flexural stiffness modelling of R.C slab strengthened by externally bonded FRP. Composites: part B 40, 758-765.

7. Foret G, Limam O (2008). Experimental and numerical analysis of RC two-way slabs strengthened with NSM CFRP rods. J.Constr.Build. Mater., 22, 2025-2030.

8. Foret, G, Limam O, Ehrlacher A (2003). RC twoway slabs strengthened with CFRP strips: experimental study and limit analysis approach. Composite structure. 60, 467-471.

9. Tan KY, Tumialan G, Nanni A (2003). Evaluation of externally bonded CFRP system for the strengthening of RC slabs. Department of civil engineering, university of Missouri, Rolla, USA.

10. Al-Rousan R, Issa M, Shabila H (2012). Performance of reinforced concrete slabs strengthened with different types and configuration of CFRP. Composites: part B 43, 510-5. 
K. M. El-Sayed, E. A. El-Kasaby, M. A. El-Maasrawy "Assessment of two-way R.C slabs strengthe ..” 